\title{
Técnicas de extracción de clavos endomedulares retrógrados de fémur rotos. Presentación de tres casos
}

\author{
Jonatan A. Lobo, Sebastián Pereira, Fernando Bidolegui \\ Servicio de Ortopedia y Traumatología, Hospital Sirio Libanés, Ciudad Autónoma de Buenos Aires, Argentina
}

\begin{abstract}
RESUMEN
Introducción: La indicación de realizar una osteosíntesis con un clavo endomedular retrógrado en las fracturas de fémur se ha incrementado en los últimos años y, con ello, la cantidad de complicaciones. Se describen tres técnicas quirúrgicas para el manejo del fragmento proximal de la osteosíntesis endomedular rota. Desde marzo de 2001 hasta enero de 2019 , se realizaron 321 osteosíntesis con clavos endomedulares retrógrados de fémur en nuestra institución. La tasa de rotura del implante asociada a una seudoartrosis fue del $0,9 \%$. Se realizaron técnicas mínimamente invasivas para la extracción del implante, preservando las partes blandas. Se logró la reosteosíntesis definitiva con la consiguiente consolidación en un tiempo medio de 140 días. Conclusiones: Las técnicas utilizadas fueron simples, seguras, mínimamente invasivas y muy reproducibles.
\end{abstract}

Palabras clave: Rotura; clavo retrógrado; fémur; extracción.

Nivel de Evidencia: IV

\section{Retrograde Femoral Intramedullary Nail Extraction Techniques. Report of Three Cases}

\begin{abstract}
Background: The indication for osteosynthesis with a retrograde intramedullary nail in femur fractures has increased in recent years and with it, the number of complications. Three surgical techniques are described for the management of the proximal fragment of the broken intramedullary osteosynthesis. From March 2001 to January 2019, 321 osteosyntheses with retrograde femoral intramedullary nails were performed at our institution. The implant rupture rate associated with nonunion was $0.9 \%$. Minimally invasive techniques were performed to remove the implant, preserving the soft tissues. Definitive reosteosynthesis was achieved with the consequent consolidation in an average time of 140 days. Conclusions: The techniques used were simple, safe, minimally invasive, and reproducible.
\end{abstract}

Keywords: Broken; nail; retrograde; femur; extraction.

Level of Evidence: IV

\section{INTRODUCCIÓN}

El uso de una osteosíntesis endomedular anterógrada se considera el tratamiento de elección para las fracturas diafisarias de fémur, se obtienen tasas de consolidación cercanas al 99\%. ${ }^{1}$ La indicación de clavos endomedulares retrógrados fue ganando terreno, ampliando las indicaciones iniciales de esta técnica y con resultados de consolidación similares. ${ }^{2-4}$

Sin embargo, algunos factores de riesgo predisponen a la falta de consolidación y la rotura del implante, como fracturas expuestas, diámetro del clavo endomedular, colocación de clavos no fresados, técnica quirúrgica, diseño de la osteosíntesis, etc. ${ }^{5-7}$

Recibido el 6-6-2019. Aceptado luego de la evaluación: 4-5-2020 • Dr. JONATAN A. LOBO • lobojonatan@ gmail.com https://orcid.org/0000-0001-6665-0063 Cómo citar este artículo: Lobo JA, Pereira S, Bidolegui F. Técnicas de extracción de clavos endomedulares retrógrados de fémur rotos. Presentación de tres casos. Rev Asoc Argent Ortop Traumatol 2021;86(3):375-391. https://doi.org/10.15417/issn. 1852-7434.2021.86.3.986 
En el escenario de una seudoartrosis, el material de osteosíntesis se ve sometido a un aumento de las fuerzas que lo predisponen a la fatiga y la rotura. ${ }^{8}$

Se han descrito diferentes técnicas quirúrgicas para extraer el clavo endomedular roto, teniendo como objetivo preservar las partes blandas mediante abordajes mínimamente invasivos, sin generar un mayor daño.

El objetivo de este artículo es describir las técnicas utilizadas para extraer la osteosíntesis, sin la apertura del foco seudoartrósico, mediante técnicas mínimamente invasivas.

\section{MATERIALES Y MÉTODOS}

En nuestra institución, entre marzo de 2001 y enero de 2019, se realizaron 321 enclavados endomedulares retrógrados de fémur. El 57,9\% (186 casos) eran fracturas diafisarias y el 42\% (135 casos), supracondíleas. En esta serie, solo había tres casos $(0,9 \%)$ de rotura del implante en presencia de una seudoartrosis. Describimos las diferentes técnicas quirúrgicas utilizadas para el manejo y la extracción del fragmento proximal del clavo que se ha roto.

\section{Caso 1}

Varón de 17 años de edad que ingresó por un politraumatismo a causa de un accidente de moto contra un automóvil, en el que sufrió una fractura transindesmal de tobillo izquierdo y una fractura de fémur derecho, tipo 32A2 de la clasificación AO, asociadas a un trauma de tórax (Figura 1).

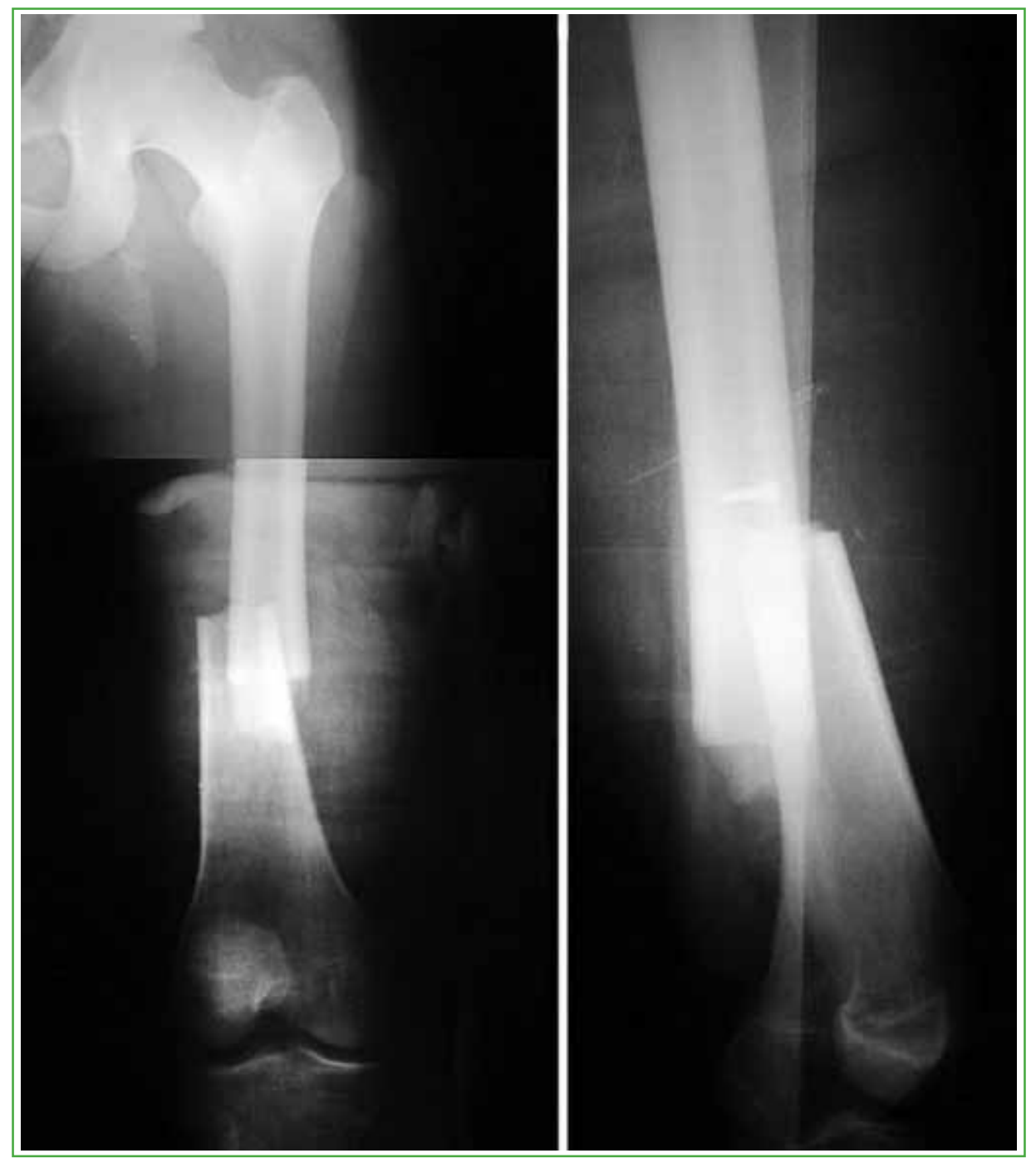

Figura 1. Radiografías anteroposterior y de perfil de fémur. Se observa una fractura de fémur 32A2. 
Inicialmente la fractura de fémur se estabilizó con un tutor externo y la fractura de tobillo, con una valva de yeso. Al octavo día se realizó la conversión del tutor externo a clavo endomedular retrógrado de fémur de $9 \mathrm{~mm}$ x 350 $\mathrm{mm}$ no fresado (Figura 2).

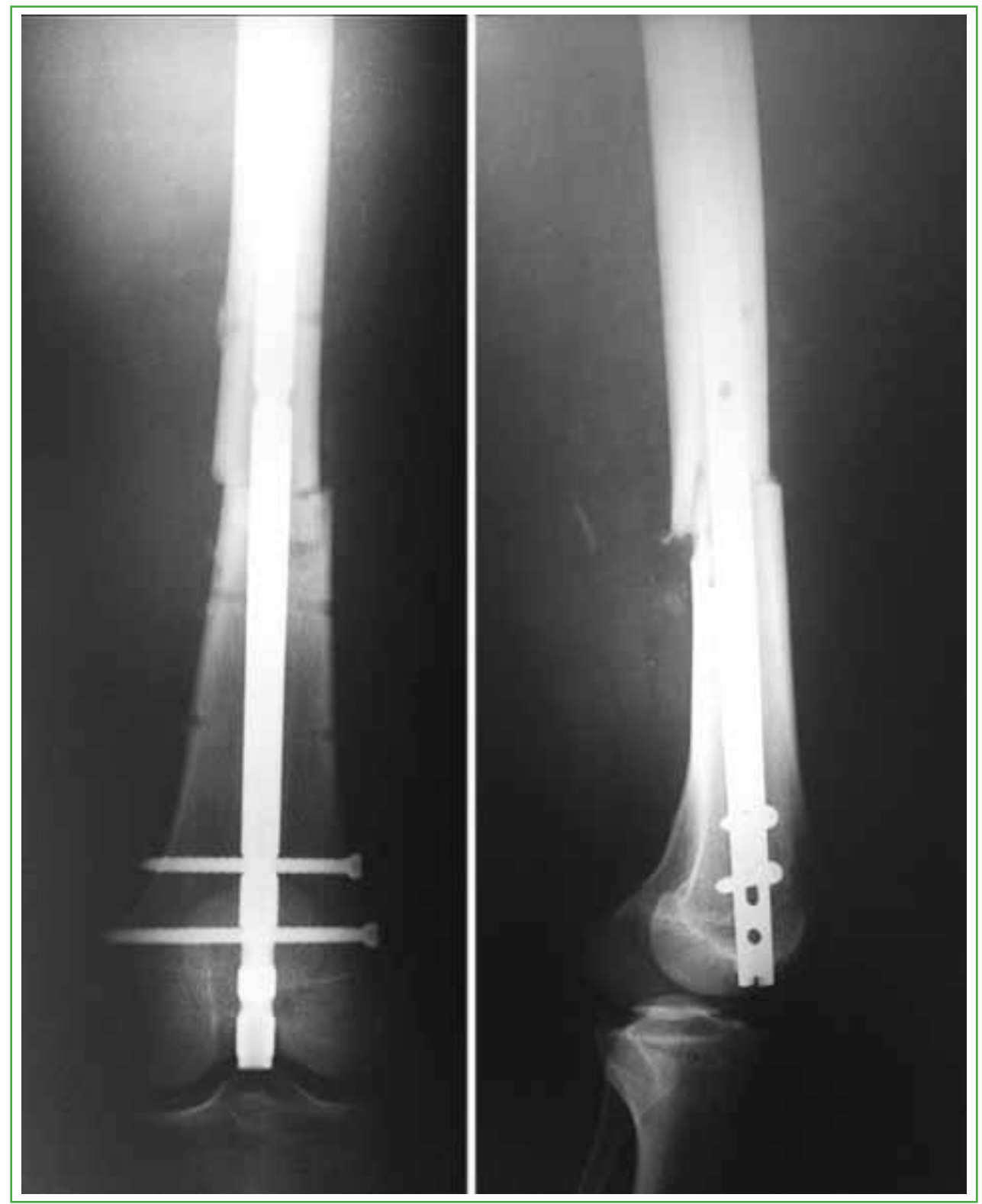

Figura 2. Radiografías anteroposterior y de perfil de fémur del posoperatorio inmediato. Se realizó reducción más osteosíntesis con un clavo endomedular retrógrado no fresado.

Al cuarto mes de la cirugía, el paciente refirió un aumento súbito del dolor en el miembro operado, durante la marcha, sin un traumatismo previo. En el control radiográfico, se observó la seudoartrosis y la rotura del implante. Se identificaron una serie de condiciones que combinadas llevaron al fracaso de la osteosíntesis. En primer lugar, la elección de un clavo endomedular de menor diámetro debido al antecedente de traumatismo de tórax. Segundo, el error de diseño del material de osteosíntesis, que presentaba un orificio de bloqueo en el tercio medio, sumado a esto, la proximidad del foco de fractura a la zona de debilidad del material de osteosíntesis. 
Estas fueron las condiciones determinantes para la seudoartrosis, la fatiga del material y la rotura del implante (Figura 3).

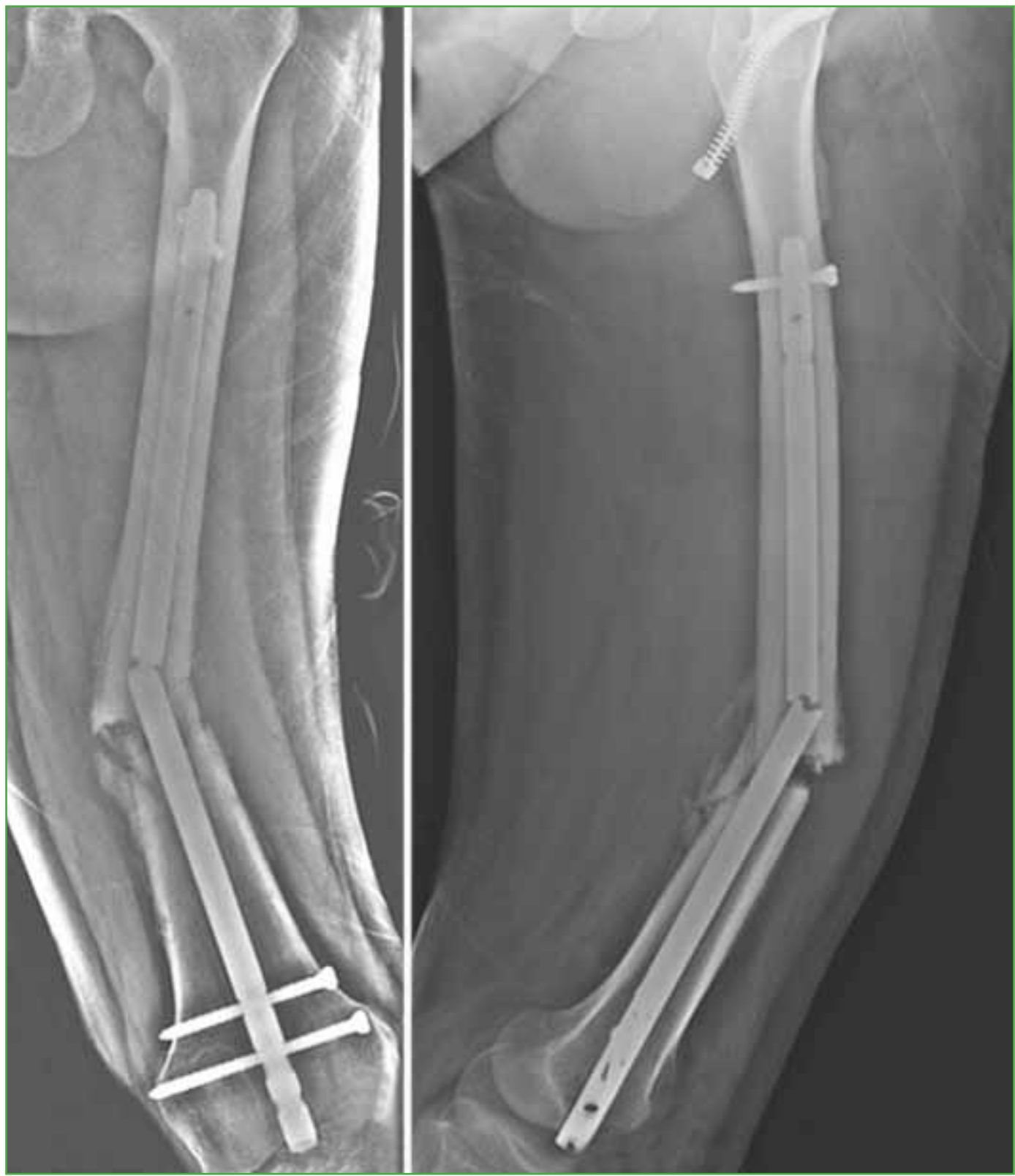

Figura 3. Radiografía anteroposterior y de perfil de fémur. Obsérvense el diámetro pequeño del clavo endomedular, la seudoartrosis sobre una zona de debilidad del implante y la rotura.

El plan quirúrgico consistió en la extracción de los fragmentos del clavo endomedular y la nueva osteosíntesis con un clavo de mayor diámetro para aportarle la estabilidad necesaria y lograr la consolidación en el tiempo.

Se realizó la extracción de los bloqueos en forma percutánea. A través del abordaje transrotuliano, se retiró el extremo distal del clavo con el extractor específico. 
Para extraer el fragmento proximal se usó un abordaje de $3 \mathrm{~cm}$ proximal al trocánter mayor. Se colocó una clavija guía de 3,8 mm roscada y, bajo control radioscópico, se realizó un correcto punto de ingreso. Se retiró la clavija guía y luego se introdujo la guía olivada por su extremo no olivado. El objetivo de esta técnica es enhebrar y lograr el atascamiento de la oliva en el extremo proximal del implante (Figura 4). La guía olivada se debe avanzar desde el trocánter mayor hasta el abordaje del fémur distal para hacer la extracción en forma retrógrada y segura, a través del abordaje transrotuliano.

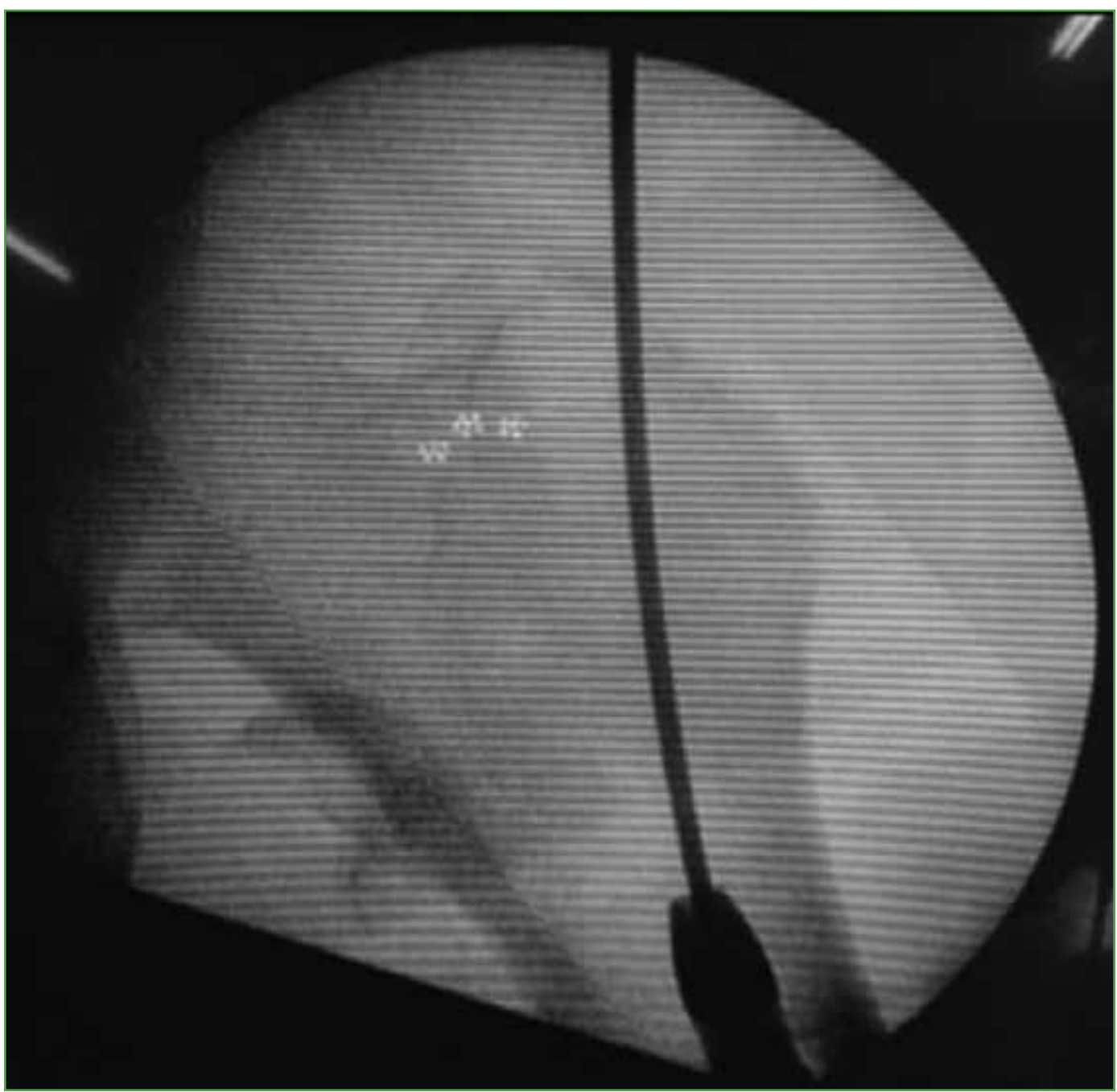

Figura 4. Imagen intraoperatoria que muestra la colocación anterógrada de la guía olivada enhebrando el fragmento proximal del clavo roto. 
A continuación, se colocó un clavo endomedular retrógrado fresado de $11 \mathrm{~mm}$ x $380 \mathrm{~mm}$. Se logró la consolidación a los cuatro meses (Figura 5).

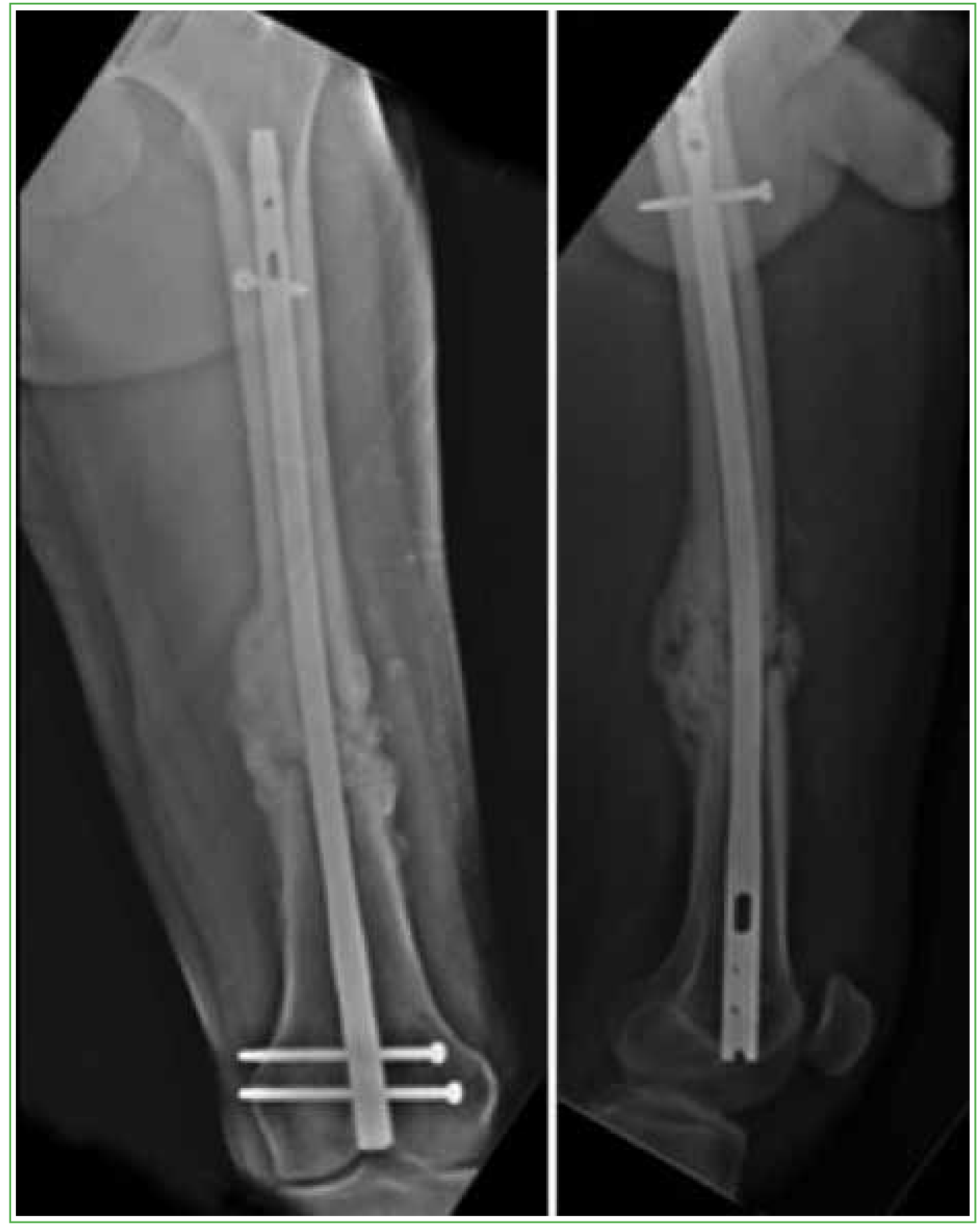

Figura 5. Control radiográfico a los 4 meses de la cirugía. Se observa la consolidación de la fractura. 


\section{Caso 2}

Mujer de 79 años de edad con antecedentes de tabaquismo y uso de alendronato, que ingresó por el Servicio de Urgencia, con dolor e impotencia funcional más deformidad del miembro inferior derecho, luego de una caída desde su propia altura. En las radiografías, se detectó una fractura diafisaria de fémur, tipo 32A2 de la clasificación AO (Figura 6).

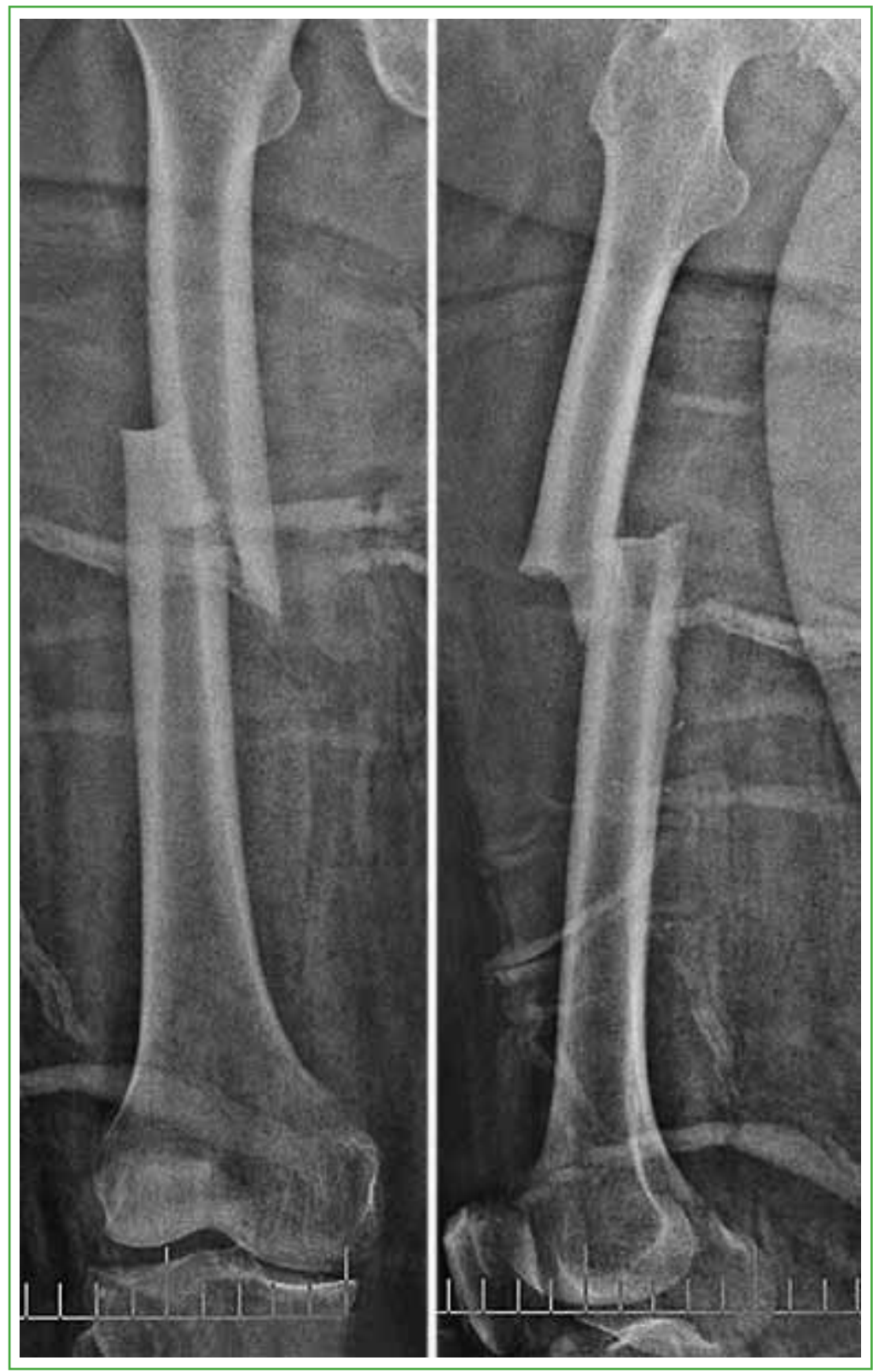

Figura 6. Radiografías anteroposterior y de perfil de fémur derecho al ingresar. Se observa una fractura diafisaria de fémur 32A2. 
Se procedió a la reducción y osteosíntesis con clavo endomedular retrógrado fresado de $11 \mathrm{~mm}$ x $340 \mathrm{~mm}$ al cuarto día del ingreso (Figura 7).

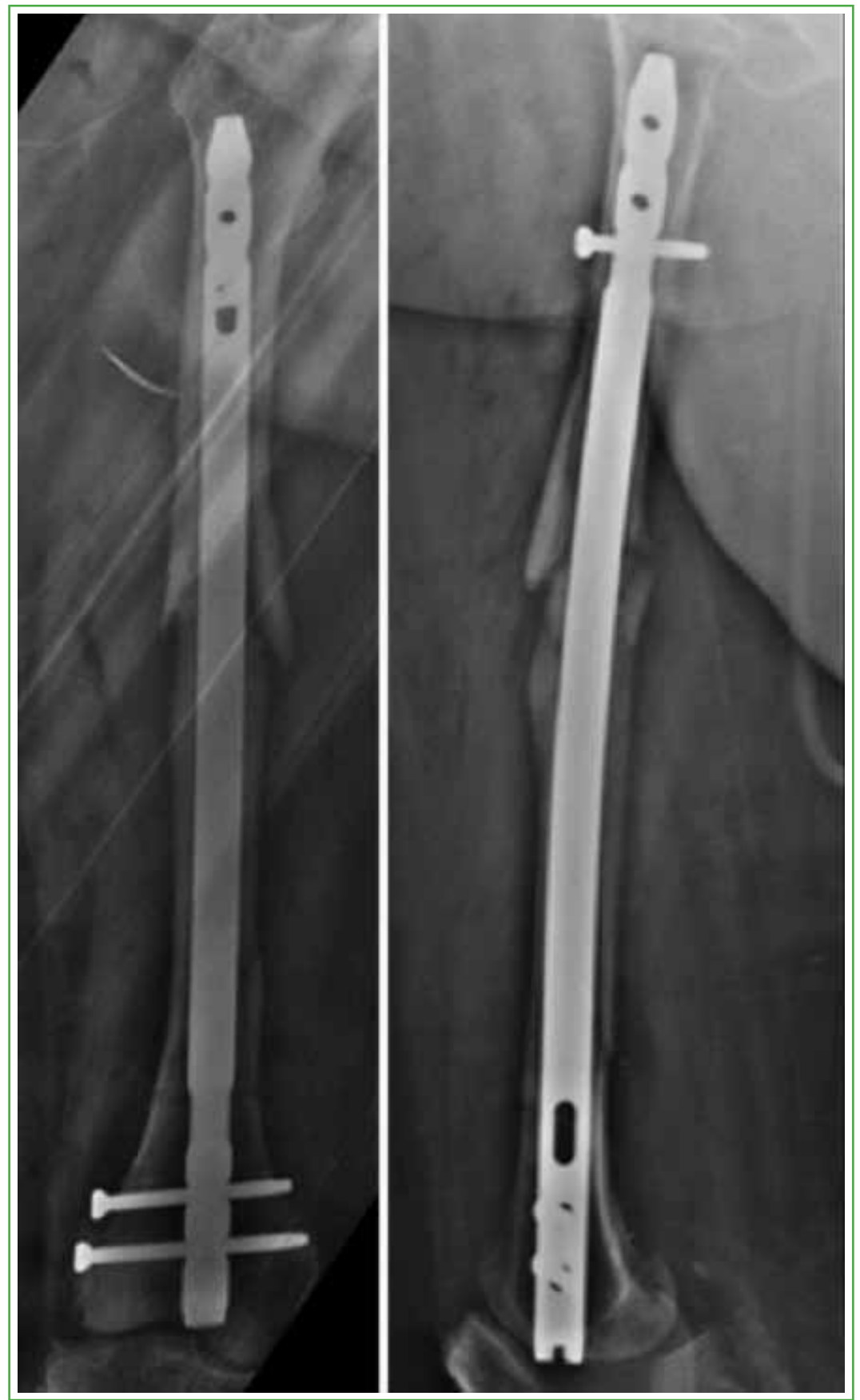

Figura 7. Control radiográfico posquirúrgico inmediato. 
En los controles radiográficos, se observó un retraso de la consolidación y su posterior evolución a la seudoartrosis y la inherente fatiga del clavo endomedular que presentaba un orificio de bloqueo cercano al foco de la fractura. Pero, al no haber síntomas ni dolor, la paciente no aceptó una segunda intervención. Al año de la intervención, ingresó en el Servicio de Urgencia con dolor e impotencia funcional, luego de una caída desde su propia altura. Se observó la rotura del implante (Figura 8).

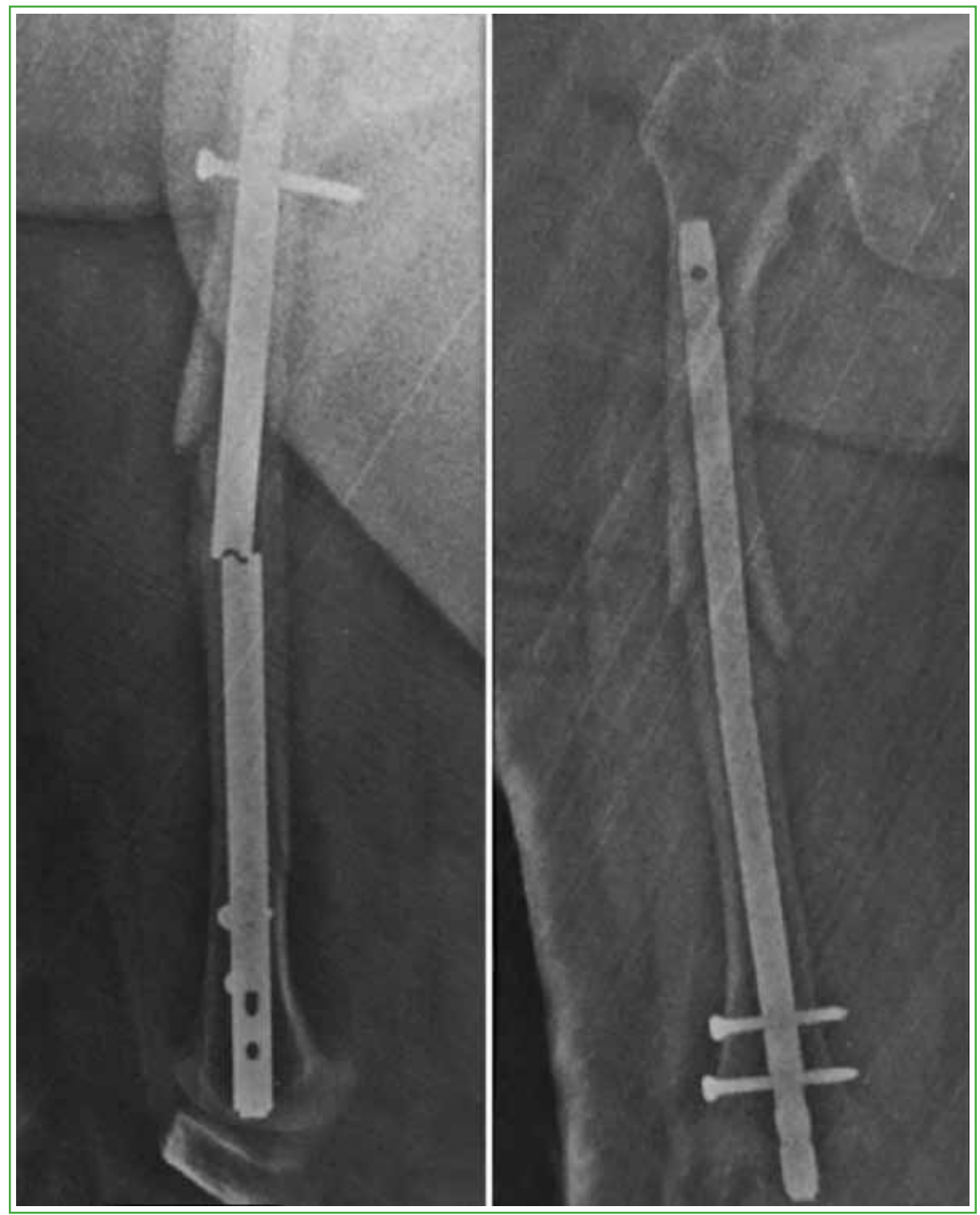

Figura 8. Radiografías anteroposterior y de perfil de fémur derecho al ingresar en el Servicio de Urgencia. Nótense la rotura del clavo endomedular y la seudoartrosis. 
El plan quirúrgico consistió en la extracción del clavo endomedular roto para realizar una reosteosíntesis con un clavo endomedular retrógrado de mayor diámetro. Luego de retirar los bloqueos distales de forma percutánea, se prosiguió con el abordaje transrotuliano y la extracción del fragmento distal del clavo con un extractor específico. Luego se introdujo la guía no olivada en forma retrógrada y se la impactó hasta el trocánter mayor. Se realizó un abordaje de $3 \mathrm{~cm}$ proximal al trocánter para poder colocar una clavija guía de 3,8 mm y así efectuar un fresado con una mecha canulada de $8 \mathrm{~mm}$. A continuación, se extrajo la guía y se realizó un doblez en forma de "anzuelo" en la punta (Figura 9).

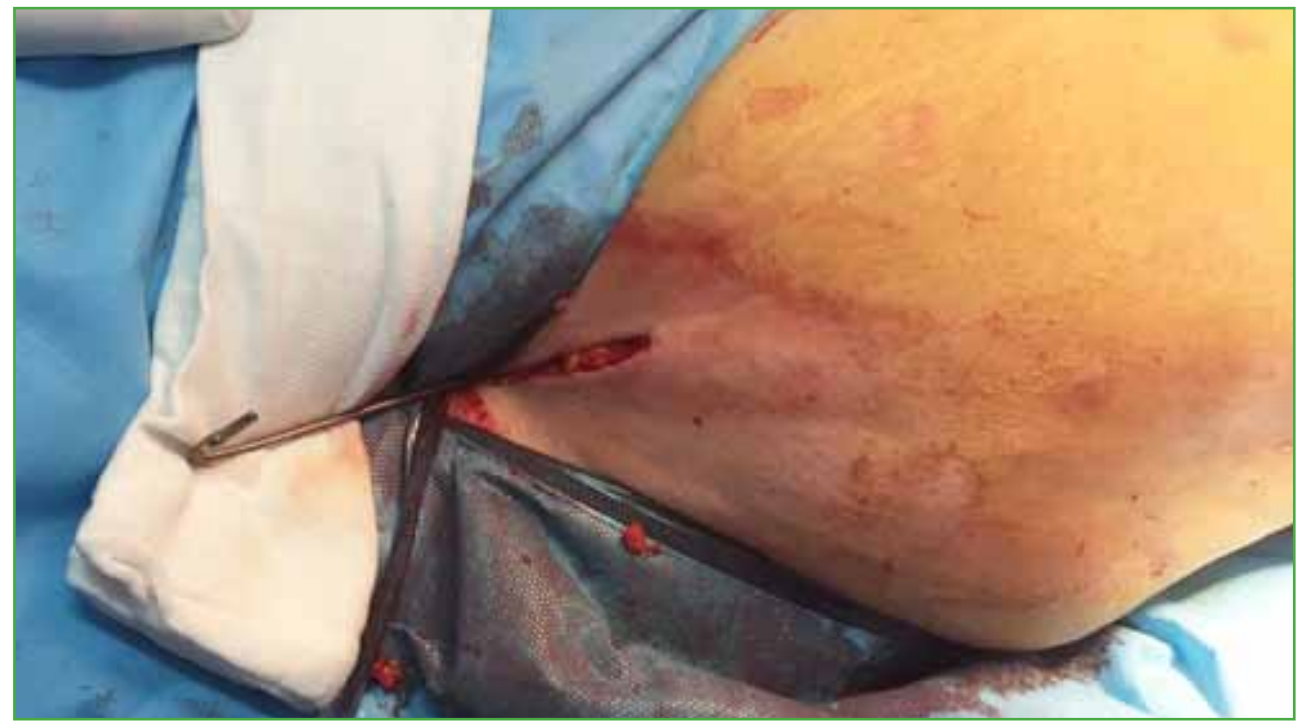

Figura 9. Abordaje proximal al trocánter mayor por donde se avanza la guía olivada y se le realiza un doblez en forma de "anzuelo".

La finalidad de esta técnica es "enganchar" con la guía en forma de anzuelo el fragmento proximal del clavo roto, para así poder hacer la extracción de manera retrógrada a través del abordaje rotuliano (Figura 10).

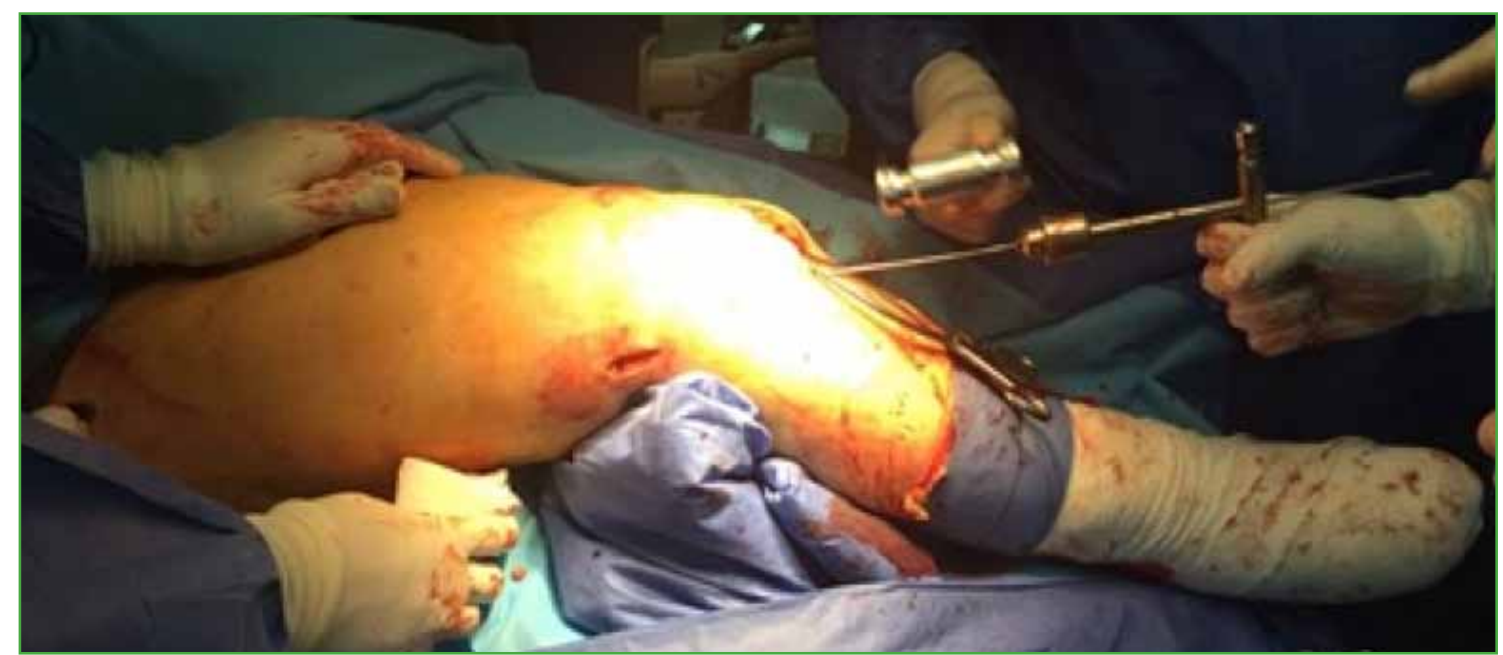

Figura 10. Extracción retrógrada de la guía en forma de "anzuelo" una vez enganchado el fragmento proximal del clavo roto. 
Se procedió al fresado creciente y a la colocación del clavo endomedular retrógrado de 14 mm x $340 \mathrm{~mm}$, sin complicaciones.

En los siguientes controles radiográficos, se confirmó la consolidación a los cinco meses (Figura 11).

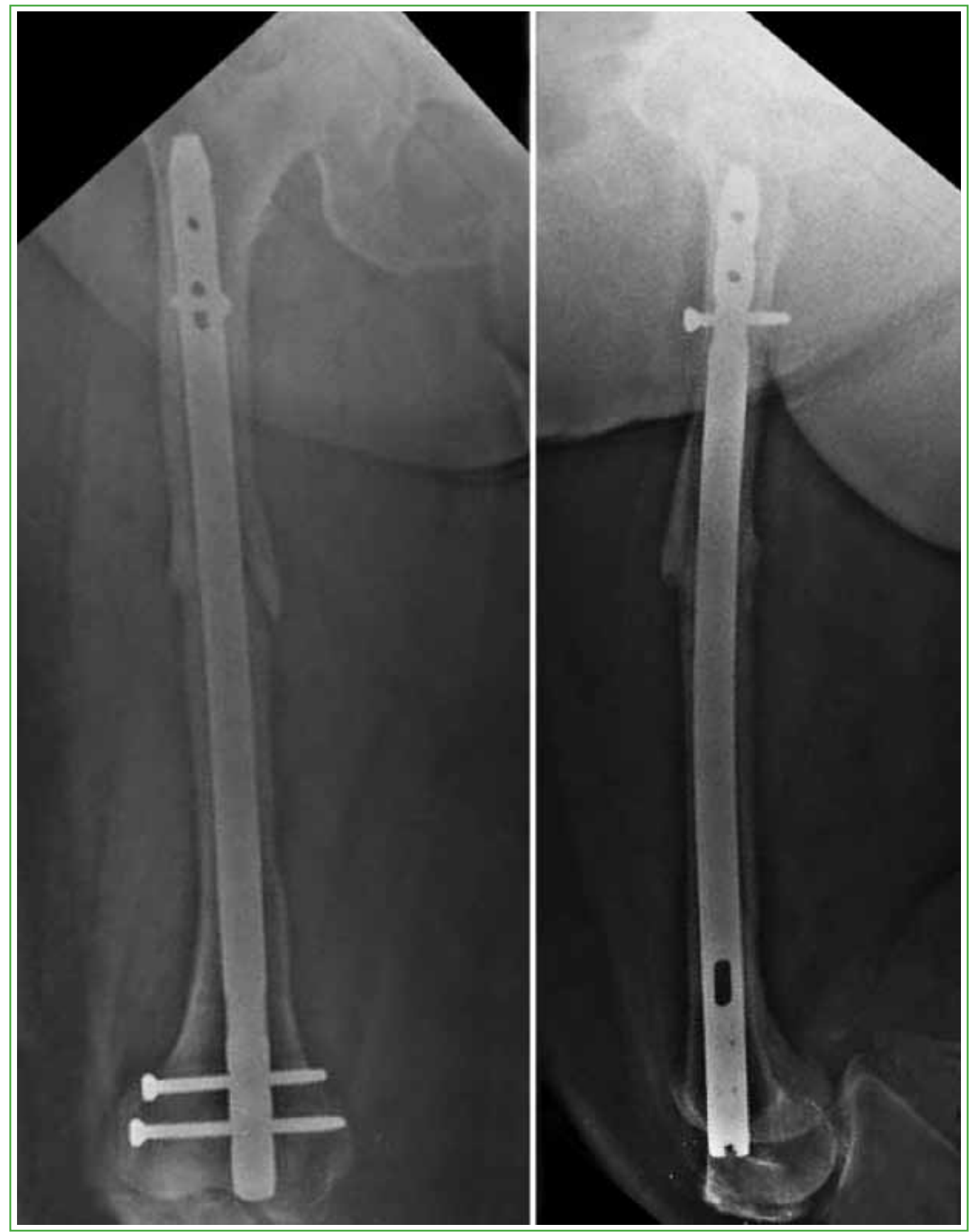

Figura 11. Control radiográfico a los 5 meses de la cirugía. Hay signos de consolidación ósea. 


\section{Caso 3}

Mujer de 52 años, fumadora, obesa con un índice de masa corporal de 42 y diabética. Acudió por un politraumatismo debido a una colisión de moto contra automóvil, en la que sufrió un traumatismo craneoencefálico, fracturas costales, fracturas en ambos antebrazos y húmero izquierdo, una luxo-fractura expuesta grave de tobillo derecho y una fractura diafisaria de fémur izquierdo, tipo 32A2 de la clasificación AO.

Se procedió a la estabilización inicial con un tutor externo para la luxo-fractura de tobillo y el fémur, y la inmovilización con valva de yeso para los miembros superiores. Al noveno día de internación, se realizó la conversión de tutor externo a clavo endomedular retrógrado fresado de $10 \mathrm{~mm}$ x $340 \mathrm{~mm}$.

A los dos años del accidente, ingresó en el Servicio de Urgencia con dolor y dificultad para caminar, sin un antecedente traumático. Se observó una seudoartrosis asociada a la rotura del clavo endomedular (Figura 12).

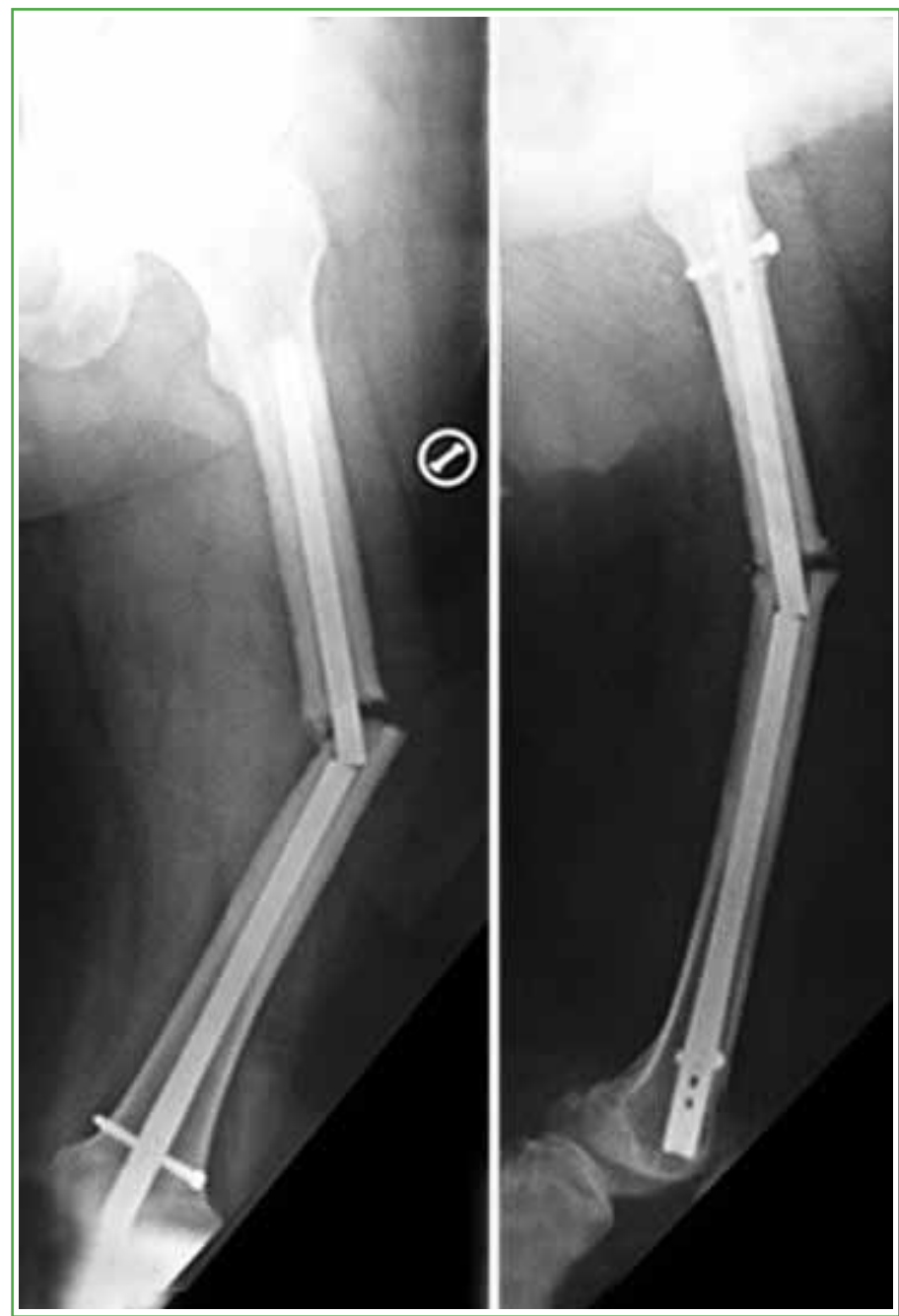

Figura 12. Control radiográfico al ingresar en el Servicio de Urgencia. Se observa la rotura del implante asociada a una seudoartrosis.

Se decidió retirar el material y efectuar la reosteosíntesis con un clavo endomedular retrógrado utilizando un solo abordaje.

Se retiraron los bloqueos de forma percutánea y el fragmento distal del clavo por el abordaje rotuliano con el extractor específico. Luego se introdujo, en forma retrógrada, una guía endomedular no olivada a través del fragmento proximal del clavo hasta sobrepasar la punta del clavo aproximadamente $6 \mathrm{~cm}$ (Figura 13A). 
El objetivo de esta técnica es introducir e impactar otra guía no olivada de menor diámetro hasta lograr el atascamiento de las dos guías (Figura 13B).

Una vez logrado el atascamiento, se traccionó de la primera guía que se colocó inicialmente, para luego extraer el fragmento proximal del clavo (Figura 13C), mediante un solo abordaje y sin complicaciones (Figuras 13D). En la Figura 13E, se observa el atascamiento eficaz de ambas guías.
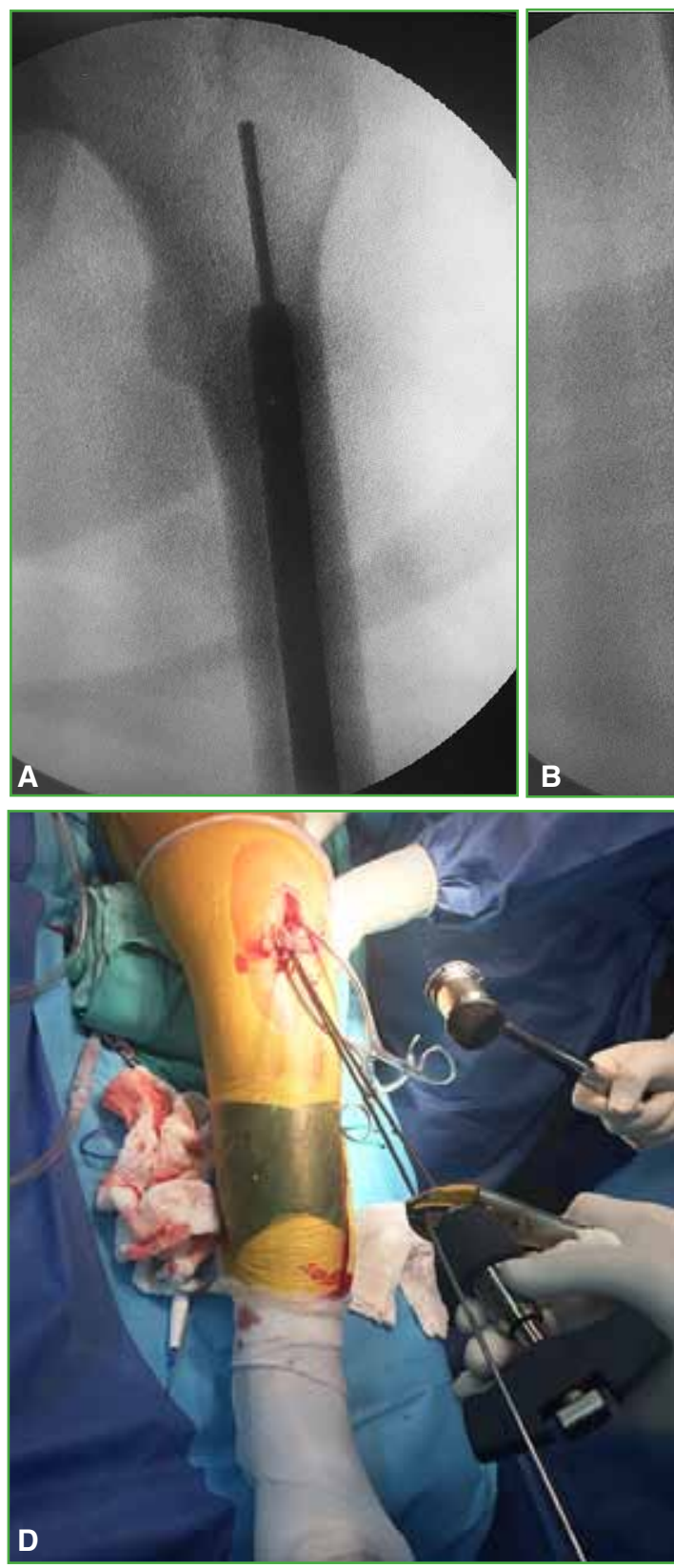
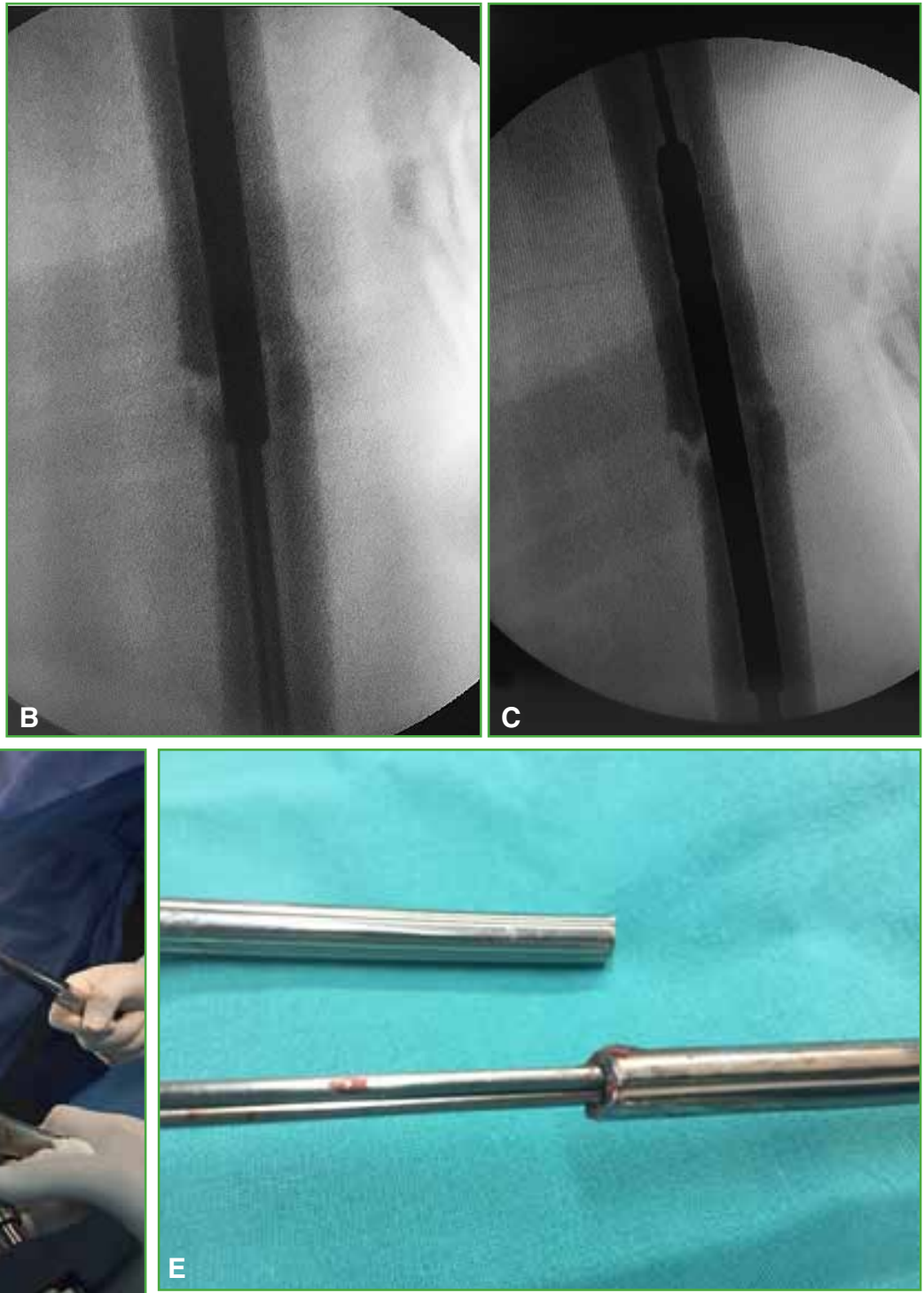

Figura 13. A. Imagen intraoperatoria en la que se evalúa la correcta colocación de la guía endomedular hasta sobrepasar la punta del clavo. B. Colocación de la segunda guía de menor diámetro, logrando el "atascamiento" de ambas guías al fragmento proximal del clavo roto. C. Extracción del fragmento proximal mediante tracción de la primera guía endomedular colocada. D. Correcta extracción retrógrada del fragmento del clavo roto, a través de un solo abordaje. E. Imagen que muestra el bloqueo efectivo de las guías de diferentes tamaños. 
Se procedió al fresado y la colocación del clavo de mayor diámetro según técnica (Figura 14).

La paciente evolucionó favorablemente y se constató la consolidación a los seis meses en las radiografías de control (Figura 15).

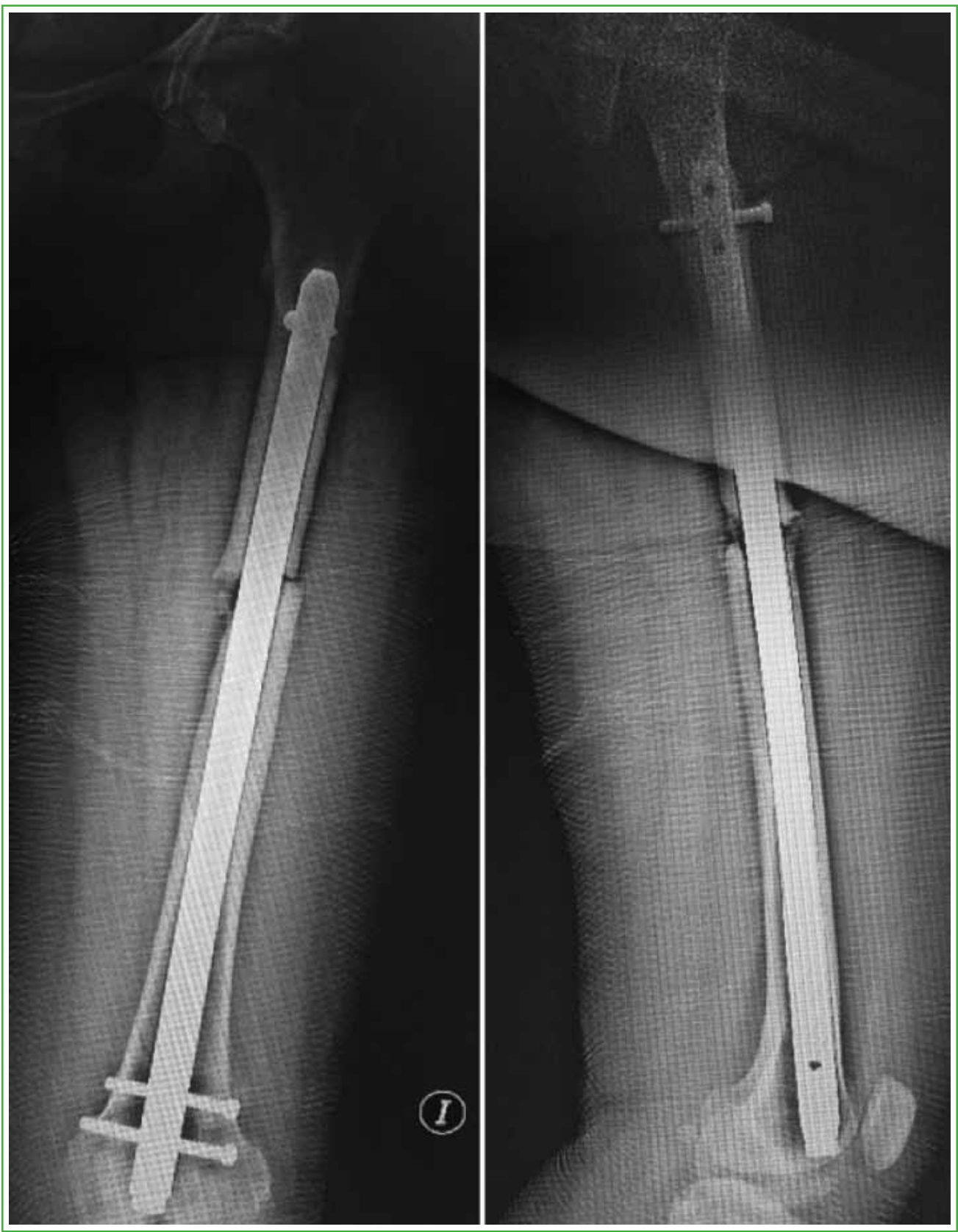

Figura 14. Control posoperatorio inmediato con un clavo retrógrado de mayor diámetro. 


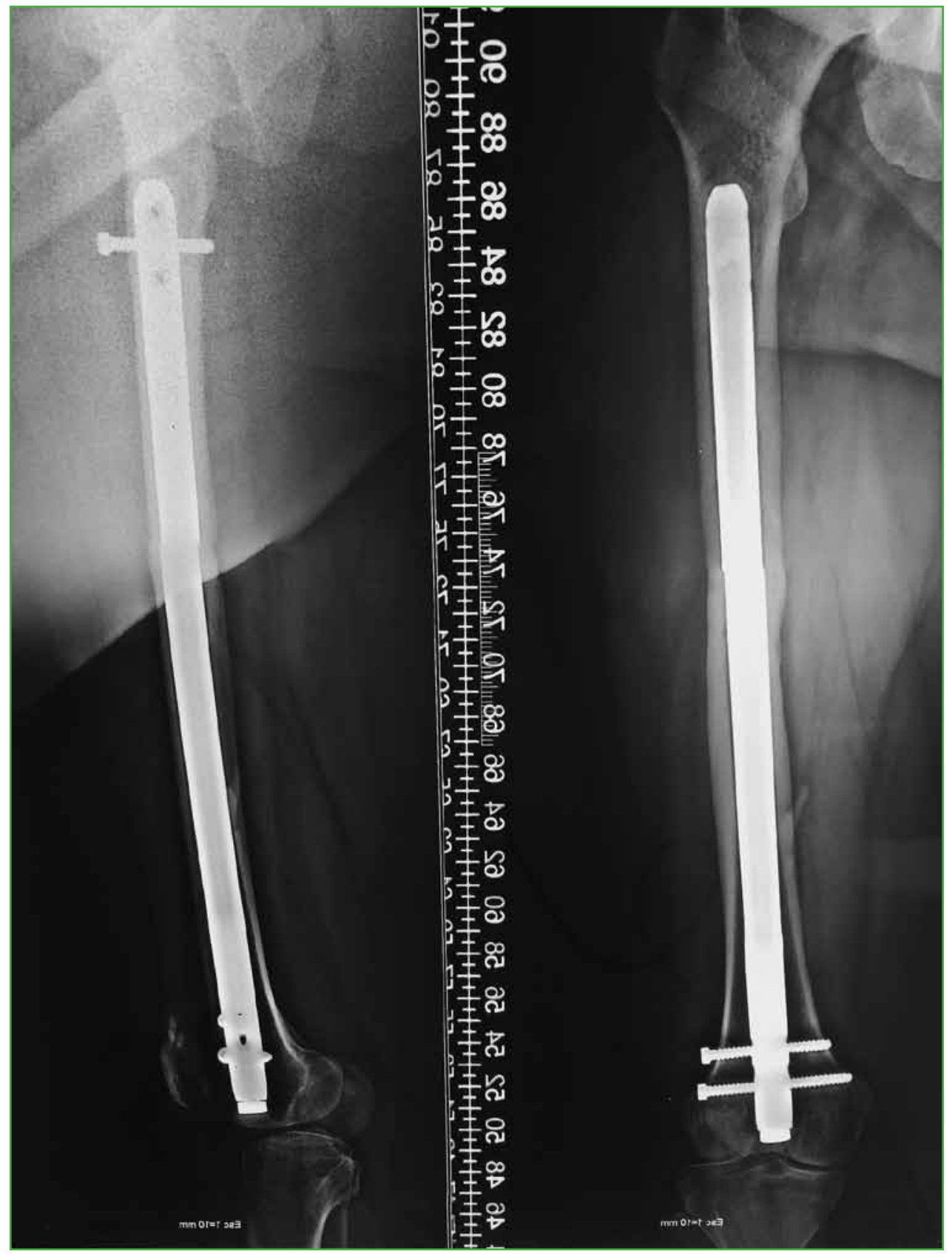

Figura 15. Control a los 6 meses de la cirugía. Se observan signos de consolidación ósea.

\section{DISCUSIÓN}

Se han descrito muchas técnicas para extraer el fragmento distal de un clavo anterógrado roto de fémur, pero es muy poca la bibliografía sobre este tipo de complicación en clavos retrógrados de fémur.

Describimos tres técnicas para extraer el fragmento proximal de un clavo retrógrado roto. La decisión de realizar una técnica u otra se basó en su practicidad y efectividad, tratando de proteger las partes blandas y de ir aumentando la complejidad de las técnicas según amerite el caso. 
Inicialmente, intentamos la extracción mediante un solo abordaje, colocando dos guías endomedulares a través del abordaje transrotuliano, buscando el "atascamiento" de estas en el fragmento proximal. Si esta técnica no fuera eficaz, como segunda opción, colocamos la guía olivada, por su extremo no olivado, a través de un nuevo abordaje sobre el trocánter mayor, para hacer la extracción retrógrada. La siguiente técnica consiste en colocar la guía endomedular a través del abordaje rotuliano, extraerla por el trocánter mayor y se crea un anzuelo sobre la punta de la guía para poder "enganchar" el fragmento del clavo.

En 1988, Franklin y cols. ${ }^{9}$ describieron una técnica revolucionaria para la extracción de clavos rotos. Utilizaron osteótomos de $50 \mathrm{~cm}$ de largo para realizarle un doblez con forma de anzuelo a $2 \mathrm{~cm}$ de la punta. Esta técnica logra un cambio en las cirugías de rescates de osteosíntesis, ya que permite preservar las partes blandas sin una gran desperiostización al abrir el foco seudoartrósico para extraer el fragmento distal del clavo roto utilizando instrumentales básicos, como pinza de agarre, clamps o fórceps. Como conclusión refieren que esta técnica es sumamente segura y eficaz, y elimina por completo la necesidad de realizar la apertura del foco para extraer el fragmento del clavo.

Autores, como Brewster y cols., ${ }^{10}$ Hak y cols., ${ }^{11}$ y Blake ${ }^{12}$ describieron técnicas para la extracción de la osteosíntesis que se rompió utilizando dos guías endomedulares. Una guía con forma de anzuelo y otra guía olivada de menor tamaño, que debía introducirse hasta sobrepasar la punta del clavo roto, para luego impactar la otra guía endomedular y así aumentar las fuerzas de atascamiento para poder hacer la extracción de manera más eficiente. En sus series, no describen complicaciones y como ventaja mencionan la simplicidad de la técnica sin necesidad de nuevos abordajes.

En 2004, Magu y cols. ${ }^{13}$ describen una técnica innovadora para extraer clavos anterógrados utilizando una guía endomedular olivada junto con una arandela a través de un abordaje transrotuliano, buscando el atascamiento de esta sobre la punta del clavo. La ventaja de esta técnica sobre las demás es que genera un mayor grip al realizar la extracción. Esta técnica es fácil de reproducir y se lleva a cabo de manera anterógrada para la extracción de clavos retrógrados.

En 2006, Karladani ${ }^{14}$ publica una técnica de extracción en la que, en un primer paso, coloca la guía endomedular olivada pasando el fragmento del clavo roto, luego coloca un tornillo de $3,5 \mathrm{~mm}$ de $12 \mathrm{~mm}$ de largo en el orificio de bloqueo atravesando la primera cortical, y queda fijo únicamente al clavo. Luego, se retira la guía endomedular olivada buscando el atascamiento de la oliva al tornillo. En la revisión bibliográfica y el reporte de casos publicado por Abdelgawad y Kanlic, ${ }^{15}$ en 2013, mencionan esta técnica como su primera opción, ya que es fácilmente reproducible y una de las más seguras. En nuestra opinión, es una técnica arriesgada y sumamente demandante, y las posibles complicaciones son que el tornillo se salga del orificio de bloqueo del clavo y quede alojado en la cavidad endomedular con la posibilidad de lesionar las corticales internas del fémur al hacer la extracción.

En 2008, Acharya y cols. ${ }^{16}$ publicaron una serie de dos casos de rotura de clavos anterógrados, utilizando una guía endomedular doblada en forma de anzuelo para extraer el fragmento distal. Concluyen en que es una técnica que se puede utilizar para la extracción de cualquier clavo endomedular, pero, para poder extraer un clavo retrógrado, nosotros modificamos esta técnica realizando un abordaje sobre el trocánter mayor para poder extraer la guía, hacer el doblez en forma de anzuelo y así poder "enganchar" el fragmento proximal roto y efectuar la extracción retrógrada de manera satisfactoria y sin complicaciones.

En el metanálisis de Whalley y cols. ${ }^{17}$ se citan 35 artículos con 11 técnicas descritas. Refieren no llegar a una conclusión sobre cuál es la técnica más eficaz, y hacen referencia a la habilidad del cirujano para elegir la técnica que más se adapte a cada situación y la necesidad de ir cambiando las técnicas a medida que se lleva a cabo el procedimiento.

\section{CONCLUSIÓN}

Las técnicas que describimos son eficaces, simples, con una mínima agresión de partes blandas y no requieren instrumental sofisticado. Por eso, recomendamos considerar estas técnicas al planificar la extracción de un clavo retrógrado roto, utilizando materiales e instrumental que todo quirófano puede llegar a contar.

Conflicto de intereses: Los autores no declaran conflictos de intereses. 


\section{BIBLIOGRAFÍA}

1. Winquist RA, Hansen ST Jr, Clawson DK. Closed intramedullary nailing of femoral fractures. A report of five hundred and twenty cases. J Bone Joint Surg Am 1984;66(4):529-39. PMID: 6707031

2. Pereira S, Lugones A, Vindver GI, Bidolegui FM. Enclavado endomedular retrógrado en fracturas diafisarias de fémur: indicaciones, técnica y resultados. Rev Asoc Argent Ortop Traumatol 2014;79(4):210-17. https://doi.org/10.15417/340

3. Sanders R, Koval KJ, DiPasquale T, Helfet DL, Frankle M. Retrograde reamed femoral nailing. J Orthop Trauma 1993;7(4):293-302. https://doi.org/10.1097/00005131-199308000-00001

4. Janzing HM, Stockman B, Van Damme G, Rommens P, Broos PL. The retrograde intramedullary nail: prospective experience in patients older than sixty-five years. J Orthop Trauma 1998;12(5):330-3. https://doi.org/10.1097/00005131-199806000-00006

5. Benirschke SK, Melder I, Henley MB, Routt ML, Smith DG, Chapman JR, et al. Closed interlocking nailing of femoral shaft fractures: assessment of technical complications and functional outcomes by comparison of a prospective database with retrospective review. J Orthop Trauma 1993;7(2):118-22. PMID: 8459295

6. Tornetta P 3rd, Tiburzi D. The treatment of femoral shaft fractures using intramedullary interlocked nails with and without intramedullary reaming: a preliminary report. J Orthop Trauma 1997;11(2):89-92. https://doi.org/10.1097/00005131-199702000-00003

7. Pape HC, Remmers D, Regel G, Tscherne H. Pulmonale Komplikationen nach intramedullärer Stabilisierung langer Röhrenknochen. Einfluss von Operationsverfahren, -Zeitpunkt und Verletzungsmuster [Pulmonary complications following intramedullary stabilization of long bones. Effect of surgical procedure, time and injury pattern]. Orthopade 1995;24(2):164-72. PMID: 7753541

8. Moed BR, Watson JT. Retrograde intramedullary nailing, without reaming, of fractures of the femoral shaft in multiply injured patients. J Bone Joint Surg Am 1995;77(10):1520-7. https://doi.org/10.2106/00004623-199510000-00006

9. Franklin JL, Winquist RA, Benirschke SK, Hansen ST Jr. Broken intramedullary nails. J Bone Joint Surg Am 1988;70(10):1463-71. PMID: 3198670

10. Brewster NT, Ashcroft GP, Scotland TR. Extraction of broken intramedullary nails--an improvement in technique. Injury 1995;26(4):286. https://doi.org/10.1016/0020-1383(95)90020-x

11. Hak DJ, McElvany M. Removal of broken hardware. J Am Acad Orthop Surg 2008;16(2):113-20. https://doi.org/10.5435/00124635-200802000-00009

12. Blake SM. A technique for the removal of the distal part of a broken intramedullary nail. Ann R Coll Surg Engl 2009;91(2):169-70. https://doi.org/10.1308/rcsann.2009.91.2.169

13. Magu NK, Sharma AK, Singh R. Extraction of the broken intramedullary femoral nail--an innovative technique. Injury 2004;35(12):1322-3. https://doi.org/10.1016/S0020-1383(03)00314-0

14. Karladani AH. Removal of a broken nail using a guide wire and a screw. Acta Orthop 2006;77(6):986-8. https://doi.org/10.1080/17453670610013330

15. Abdelgawad AA, Kanlic E. Removal of a broken cannulated intramedullary nail: review of the literature and a case report of a new technique. Case Rep Orthop 2013;2013:461703. https://doi.org/10.1155/2013/461703

16. Acharya M, Alani A, Almedghio S. The Fish Hook Technique of extracting broken intramedullary nails. Acta Orthop Belg 2008;74(5):686-8. PMID: 19058706

17. Whalley H, Thomas G, Hull P, Porter K. Surgeon versus metalwork--tips to remove a retained intramedullary nail fragment. Injury 2009;40(7):783-9. https://doi.org/10.1016/j.injury.2008.12.009 